\title{
Sharing Economy Platforms' Pricing Strategies and Decision Preferences: The Example of DiDi
}

\author{
Yanli Guo*, Jianbin Chen, Yingying Zhou, Jie Geng \\ Business College of Beijing Union University, Beijing, China \\ Email: *yanli.guo@buu.edu.cn
}

How to cite this paper: Guo, Y. L., Chen, J. B., Zhou, Y. Y., \& Geng, J. (2020). Sharing Economy Platforms' Pricing Strategies and Decision Preferences: The Example of DiDi. Open Journal of Business and Management, 8, 1641-1656.

https://doi.org/10.4236/ojbm.2020.84104

Received: June 17, 2020

Accepted: July 21, 2020

Published: July 24, 2020

Copyright $\odot 2020$ by author(s) and Scientific Research Publishing Inc. This work is licensed under the Creative Commons Attribution International License (CC BY 4.0).

http://creativecommons.org/licenses/by/4.0/

\begin{abstract}
The sharing economy model is a new trend in the development of the Internet economy and has been widely applied in transportation industry, showing an increase in its popularity. The proliferation of the sharing economy's application prompts an investigation of its mechanisms and implications. Using $\mathrm{DiDi}$, a car-sharing company, as an example, and a revenue sharing model built for the study, this paper analyzes the main factors influencing the pricing strategy choices and the decision-making behaviors of sharing economy platforms, then analyzes the factors influencing the risk of resource and customer loss. The following conclusions are drawn: First, when faced with different optimal price choices to ensure revenue maximization for platform only, versus both the platform and the providers, pricing decision of sharing economy platform is related to the sharing costs of providers and the price elasticity of expected transaction volumes. Second, a sharing economy platform tends to choose a low price strategy when the user scale (or number of users) does not exceed the scale threshold (user base), which represents the positive feedback point; otherwise, it involves high price strategies. Third, the decision preferences of a sharing platform will vary according to different marketing stages. The contributions reveal that the price-setting decisions of platform are influenced by sharing costs of providers, user scale and price elasticity.
\end{abstract}

\section{Keywords}

Sharing Economy, Pricing Strategies, Revenue Maximization, Price Elasticity

\section{Introduction}

Various sharing platform models are becoming ever more popular and changing the face of business models, prompting endeavors to understand their mecha- 
nisms, influencing factors, and profit determinants, among others, due to the growing application of Internet-based services and similarly increasing number of users of such platforms. The objective of this paper is to clarify the price-setting mechanism of sharing economy platforms, to analyze the main factors of pricing strategy choices, and their decision-making preferences. The study reveals implications for sharing economy business managers, specifically in terms of giving insight about the best price-setting practices under different market situations.

According to finance.china.com.cn (finance@china.org.cn, 2018), in 2017, DiDi completed 7.43 billion rides for 450 million users in over 400 cities across China - which equates to five rides per person in China-and over 1.05 billion seats were shared by DiDi's two core carpooling services, DiDi Hitch and ExpressPool. DiDi is a typical transportation sharing service, especially its operation and payment models. At any point, a DiDi use can become a service provider (car owner), or a service receiver (passenger). The demand and supply of transport for the public has been effectively docked through DiDi platform. As a service promotion strategy, DiDi Hitch kept its pricing low through various subsidies and attracted many car owners and passengers. In April 2017, DiDi raised its prices to cover for trip rejections and detours, to benefit the drivers. However, as their prices increased, passengers began to complain.

Pricing mechanisms affect the benefits of both service providers and receivers: lower prices reduce the earning of car owners and platforms, while higher prices cause a decline in the passengers' trip requests (Kung \& Zhong, 2017). Therefore, it is important for sharing economy platforms to establish reasonable pricing strategies that optimize the returns of both service providers and the platforms, without restraining or sabotaging demand. The focus of this paper is on the pricing mechanism of sharing economy platforms, the analyses of the main factors of pricing strategy choices, and their decision-making preferences.

\section{Literature Review}

The sharing economy refers to the economic model in which individuals, organizations, or enterprises share their spare physical resources or cognitive surpluses through the Internet to provide services and obtain income at marginal costs that are lower than of professional organizers (Puschmann \& Alt, 2016). The theory of the sharing economy was firstly proposed by Professor Martin L. Weitzman in 1984. He considered that the essence of the sharing economy was a wage system with marginal costs that are less than the average cost of labor (Weitzman, 1984). Subsequently, Meade (1986) further studied the sharing economy from the practical perspective. The specific forms of the sharing economy discussed in this book include employee stock ownership, laborer management cooperation, revenue sharing systems, profit sharing systems, labor and capital cooperation systems, etc. The sharing economy relies on the Internet and the sharing economy platform has cross-network externalities (Weyl, 2010). Today, the fast iterative of technologies such as the Internet, ICT, Cloud compu- 
ting, and Big Data has given the sharing economy a more multidimensional and deeper connotation (Frenken \& Schor, 2017; Wu \& Shen, 2015) and form (Zervas et al., 2013). Many scholars have researched the concept of the sharing economy from different perspectives (Andreoni, 2020), thus, it has been gradually extended from the production field to the consumption field (Hamari et al., 2016; Selloni, 2017), and discussions about the relevant theories have been deepened. For example, based on the view of $\mathrm{Li}$ and $\mathrm{Lu}$ (2015), the sharing economy is a kind of "collaborative consumption" system with a basic "use of ownership" concept, an "individual versus individual "trading business model, and based on new information consumption. On the other hand, Xie (2015) believed that the essence of the sharing economy is knowledge economy and analyzed the nature of the sharing economy based on Hayek's knowledge theory (Hayek, 1945). Other scholars studied the essence and connotation of the sharing economy from the perspective of matching supply and demand information (Pang \& Chen, 2017), transaction costs (Henten \& Windekilde, 2016; Qiao \& Zhang, 2016), and transfer of tenure (Zheng, 2016). Although the above studies have different viewpoints they all agree that the essence of the sharing economy is the separation of controlling power and usage rights, with the purpose of increasing the frequent usage of spare resources and optimize the efficiency of resource allocation (Jiang \& Yin, 2019; Wu \& Fang, 2017).

In summary, the basic elements of the sharing economy are resource sharing, efficiency improvement, and resource conservation. The platform, product or service providers, and demanders of the goods or services are the subjects of the sharing economy (Ma \& Xu, 2018). The question then is how can these elements be organically coordinated to maximize the benefits of the various entities (subjects) in the sharing economy? Some scholars believe that the pricing strategy of the platform is crucial (Lin, 2017; Wang \& Nicolau, 2017). Different pricing strategies directly affect the number of transactions between the demander and the provider on the platform, thereby affecting the interests of the various entities of the sharing economy platform. In recent years, the rise of sharing economy platforms has prompted more and more scholars to explore the pricing strategies of sharing economy platforms from a practical perspective. As early as 2006, Armstrong studied the pricing model of monopoly and competition platforms from a fixed membership fee perspective, which showed that the optimal pricing of the platform was equal to the cost of the goods or service to suppliers minus the cross-returns brought by the customers. The total price of the platform is the sum of the social optimal price and the benefits of the monopoly power on both sides of the market.

Based on the two-sided markets theory, Wu and Fang (2017) developed the pricing model of monopolistic and differentiated competitive platforms. They also studied the user scales and incomes of differentiated competitive platforms from the perspective of different user affiliations and considered the matching efficiency of the platform to meet demand and supply. Their results showed that 
efficiency, network externality and user scale affected competitive platforms' pricing strategies and that these platforms could increase profits by increasing the degree of differentiation. Additionally, Li and Zhao (2017) studied the strategy combination of optimal pricing, user number, corresponding platforms' profits when adopting membership fee system, a transaction fee system, and a two-part fee system in the service demand-side of the platform by establishing an economic model for maximizing the profit. Qi (2017) studied the pricing strategy of the mobile taxi platform and analyzed the optimal price of the monopoly platform under the unified pricing and variable pricing strategies. Gibbs et al. (2017) built a hedonic pricing model to analyze the Airbnb's pricing strategies. Zhong, Xiao, and Huang (2018) also discussed the optimal pricing and continuous profit model of the sharing economy platform by taking the bicycle-sharing system as an example.

For the pricing strategy of sharing economy platforms, existing researches mostly study the factors of the pricing strategy but lack comprehensive consideration for optimal service pricing and income distributions for the supply side, the demand side, and the platform. It is necessary to carry on a systematic in-depth exploration of the factors on the pricing strategy of sharing economy platforms, such as the cost of the supplier, the user's decision-making preferences, and user scales. Based on the newsboy model, this paper studies the price decision behaviors of sharing economy platforms and analyses how sharing economy platforms maximize revenue through optimal service price setting.

\section{Methods}

There are several main differences between sharing economy and traditional economy platforms. Firstly, the degree of information sharing is different (Li, 2015; Wang, 2017). Sharing economy platforms greatly improve the degree and efficiency of information sharing, greatly reduce the degree of information asymmetry between providers and demanders, and greatly improve the efficiency of information searching for consumers. Secondly, the transparency of capital flows is different (Guo \& Yan, 2012; Yan et al., 2012; Guo et al., 2013). Compared with traditional economic models, platform-based business models make the flow of revenue sharing transparent, Such that those who provide services via sharing economy platforms can easily access information on order volume and demand changes.

\subsection{Basic Symbols}

The concept of sharing economy includes three main players: the providers of goods or services, the demanders of those goods and services, and the sharing economy platform (Ma \& Xu, 2018). A sharing economy platform, as an intermediary (Kannisto, 2017), builds a link between the providers and demanders of shareable goods and services. Each user of the shared resources can become a provider or a demander and the concept of upstream and downstream tends to 
blur the supply chain (Shao \& Wang, 2017). Therefore, in this paper, the revenue sharing model is constructed to analyze the pricing strategies of sharing economy platform from the perspective of the entire supply chain with dual user identities (see Figure 1).

The basic symbols of our model are as follow:

$P$ : Price of shared goods or service;

$\Phi$ : Share of proceeds ( $P$ is the cost per unit paid by the demanders, $\Phi$ is the part owned by the sharing economy platform and $1-\Phi$ represents the part owned by the providers), thus, $0<\Phi<1$;

$\pi_{1}$ : The revenue of providers;

$C_{1}$ : Fixed costs of providers who share goods or services through a sharing economy platform, such as car maintenance costs incurred by DiDi drivers;

$C_{1 f}$ : Variable costs of providers who share goods or services through a sharing economy platform, such as the fuel costs for each service rendered by DiDi drivers;

$\pi_{2}$ : The revenue earned by a sharing economy platform;

$\mathrm{C}_{2}$ : Fixed costs incurred by a sharing economy platform during the service period;

$C_{2 f}$ : Variable costs incurred by a sharing economy platform for each service.

The market demand is a random variable $(p)$, and is related to the sharing price. The distribution function of demand is $F(x, p)(x>0)$, the density function is $f(x, p)$, thus, $\partial F(x, p) / \partial p \neq 0$ for the distribution function.

\subsection{Mathematical Model}

Metcalfe's law states that the value of a network is proportional to the square of the number of connected users. Let us suppose that the user size of a sharing economy platform is $n$. The maximum volume of transactions can reach $n^{2}$ when all users of the platform are involved in the transaction (Wang \& Nicolau, 2017). Suppose $v=n^{2}$, and the expected trading volume of sharing economy platform is $S(v, p)$, so,

$$
S(v, p)=v-\int_{0}^{v} x f(x, p) \mathrm{d} x
$$

The revenue function of sharing economy platform is

$$
\pi_{2}=\left(\varnothing p-C_{2 f}\right) \times S(v, p)-C_{2} .
$$

The revenue function of providers is

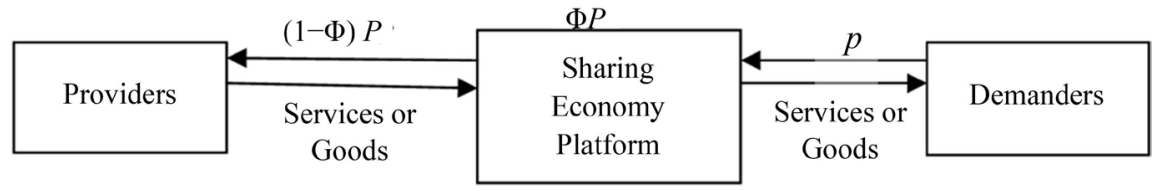

Figure 1. Revenue sharing model of sharing economy platform. 


$$
\pi_{1}=\left((1-\varnothing) p-C_{1 f}\right) \times S(v, p)-C_{1}
$$

\section{Results}

Based on the above basic model, the optimal price expression of sharing economy platforms and service providers can be calculated. That is to say, the objective function of a sharing economy platform is: $\max \left(\pi_{2}\right)$

$$
\frac{\partial \pi_{2}}{\partial p}=\varnothing S(v, p)+\left(\varnothing p-C_{2 f}\right) \frac{\partial S}{\partial p}
$$

Set $\frac{\partial \pi_{2}}{\partial p}=0$, thus

$$
p^{*}\left(\pi_{2}\right)=S(v, p) / \frac{\partial S}{\partial p}+C_{2 f} / \varnothing .
$$

The whole revenue function of a sharing economy platform and its providers is

$$
\pi=\left(p-C_{1 f}-C_{2 f}\right) \times S(v, p)-\left(C_{1}+C_{2}\right) .
$$

when the overall revenue is optimal,

$$
p^{*}(\pi)=\left(C_{1 f}+C_{2 f}\right) \frac{\partial S}{\partial p}-S(v, p) .
$$

when the objective function of the providers, $\max \left(\pi_{1}\right)$, is optimal, the price is

$$
p^{*}\left(\pi_{1}\right)=C_{1 f} /(1-\varnothing)-S(v, p) / \frac{\partial S}{\partial p} .
$$

As $F$ is a differentiable maximum, an optimal price exists for meeting the maximization of revenue. However, the sharing economy platform, as a price-maker, is not likely to make a decision based on revenue maximization for providers. When demand is stable, the optimal price is only related to the variable cost of a single transaction. It is supposed that $C_{2 f}=0$; that is, the variable cost of each additional transaction is very little (Schwieterman \& Bieszczat, 2017). Therefore the optimal price for revenue maximization for the sharing economy platform is

$$
p^{*}\left(\pi_{2}\right)=S(v, p) / \frac{\partial S}{\partial p} .
$$

If the sharing economy platform wants to engage more providers and make the decision to maximize revenue for both the sharing economy platform and the providers, the optimal price would be

$$
p^{*}(\pi)=C_{1 f} \frac{\partial S}{\partial p}-S(v, p),
$$

where, $\frac{\partial S}{\partial p}$, a derivative of expected transactions volume to price, can be used to 
indicate the average rate of change of expected transaction volume under the influence of price. According to the general theory of economics, expected transaction volume is a decreasing function of price, i.e., expected transaction volume will fall when prices rise. Therefore, it is supposed that

$$
\frac{\partial S}{\partial p}=\alpha, \alpha<0 \text {. }
$$

Then,

$$
\begin{aligned}
p^{*}\left(\pi_{2}\right) & =\frac{1}{\alpha}\left(v-\int_{0}^{v} x f(x, p) \mathrm{d} x\right) \\
p^{*}(\pi) & =C_{1 f} \alpha-\left(v-\int_{0}^{v} x f(x, p) \mathrm{d} x\right) \\
& =C_{1 f} \alpha-p^{*}\left(\pi_{2}\right) \alpha \\
& =|\alpha|\left(p^{*}\left(\pi_{2}\right)-C_{1 f}\right)
\end{aligned}
$$

Based on the above calculation, the following relationship exists between the optimal prices in two cases.

$$
\frac{p^{*}(\pi)}{p^{*}\left(\pi_{2}\right)-C_{1 f}}=|\alpha|
$$

It can be seen that the relationship between $p^{*}\left(\pi_{2}\right)$ and $p^{*}(\pi)$ depends on the value of $C_{1 f}$ and $|\alpha|$.

\section{Discussion}

Based on the above model and analysis, the effect of resource sharing, specifically sharing the costs of providers, on optimal prices, as well as the sharing economy platform's pricing decision will be discussed.

\subsection{The Effect of Costs on Optimal Prices}

Depending on the types of idle resources shared via the sharing economy platform, the variable costs of providers will be different (Nicosia et al., 2017). Some resources, such as knowledge, can be shared without too much variable cost. However, the variable costs of some resources increase with growth in the transaction amount. For example, DiDi Hitch drivers have to bear the fuel costs of each transaction. In comparison, the owners of short-term accommodation only have variable costs for each new tenant, while the variable costs of shared bikes are very little.

When the variable costs of providers $\left(C_{1 f}\right)$ are close to zero,

$$
\lim _{C_{1 f} \rightarrow 0} \frac{p^{*}(\pi)}{p^{*}\left(\pi_{2}\right)}=|\alpha| \text {. }
$$

Regardless of the variable costs of resource providers, the ratio of two optimal prices, for the maximization of the platform's revenue and the maximization of revenue for both providers and the platform, are close to $|\alpha|$. 
When the variable costs of providers must be considered, i.e., $C_{1 f}>0$, then

$$
\lim _{C_{1 f} \rightarrow 0} \frac{p^{*}(\pi)}{p^{*}\left(\pi_{2}\right)-C_{1 f}}=|\alpha| .
$$

There are two pricing options for platform: one is $p^{*}\left(\pi_{2}\right)$, representing the optimal price for the platform's revenue maximization, and the other is $p^{*}(\pi)$, the optimal price for maximizing both the providers and platform's revenues.

In the case of $C_{1 f}=0$ and $|\alpha|=1$, the two optimal prices are the same, $p^{*}\left(\pi_{2}\right)=p^{*}(\pi)$. In the case of $C_{1 f}=0$ and $|\alpha|>1$, the optimal price for the platform's revenue maximization is lower than the optimal price for maximizing the revenue of both providers and the platform, $p^{*}\left(\pi_{2}\right)<p^{*}(\pi)$. In the case of $C_{1 f}=0$ and $|\alpha|<1$, the optimal price for the platform's revenue maximization is higher than the optimal price for maximizing the revenue of both providers and the platform, $p^{*}(\pi)<p^{*}\left(\pi_{2}\right)$.

In the case of $C_{1 f}>0$ and $|\alpha|=1, p^{*}(\pi)=p^{*}\left(\pi_{2}\right)-C_{1 f}$, there is $p^{*}(\pi)<p^{*}\left(\pi_{2}\right)$.

In the case of $C_{1 f}>0$ and $|\alpha|>1, p^{*}(\pi)>p^{*}\left(\pi_{2}\right)-C_{1 f}$, if the fee paid by platform to providers is equal to the variable cost of the provider $(1-\varnothing) p=C_{1 f}$, the unit revenue of platform is $p^{*}\left(\pi_{2}\right)-C_{1 f}$.

In the case of $C_{1 f}>0$ and $|\alpha|<1, \quad p^{*}(\pi)<p^{*}\left(\pi_{2}\right)-C_{1 f}$, i.e. $p^{*}(\pi)<p^{*}\left(\pi_{2}\right)$, the platform will gain higher unit revenue.

Theorem: Faced with different choices of optimal pricing for the platform's revenue maximization or revenue maximization for both providers and the platform, the pricing decision of the sharing economy platform $\left(p^{*}\left(\pi_{2}\right)\right.$ or $\left.p^{*}(\pi)\right)$ is related to the sharing costs of providers $\left(C_{1 f}\right)$ and the price elasticity of expected transactions $(|\alpha|)$. If $C_{1 f}=0$ and $|\alpha|=1$, the two optimal prices are the same. If $C_{1 f}>0$ and $|\alpha|=1$, there is $p^{*}(\pi)<p^{*}\left(\pi_{2}\right)$, the optimal price for the platform's revenue maximization is higher. If $C_{1 f}=0$ and $|\alpha|>1$, then $p^{*}\left(\pi_{2}\right)<p^{*}(\pi)$, the optimal price for the platform's revenue maximization is lower. If $C_{1 f} \geq 0$ and $|\alpha|<1$, then $p^{*}(\pi)<p^{*}\left(\pi_{2}\right)$, the optimal price for the platform's revenue maximization is higher.

\subsection{Price-Setting Decision}

Based on the above theorem, the sensitivity of expected trading volume to price is one of the important factors for price-setting decisions by the sharing economy platform.

The formula is as follows,

$$
\alpha=\frac{\partial S}{\partial p}=\frac{\partial\left(v-\int_{0}^{v} x f(x, p) \mathrm{d} x\right)}{\partial p} .
$$

Thus, 


$$
|\alpha|=\left|v \frac{\partial F(x, p)}{\partial p}\right|=n^{2}\left|\frac{\partial F(x, p)}{\partial p}\right|
$$

The sensitivity of the expected trading volume to price is related to both the response coefficient of the stochastic demand distribution function to price $\left(\frac{\partial F(x, p)}{\partial p}\right)$ and the user scale of the sharing economy platform (n).

\subsection{The Impact of User Size on Optimal Pricing Decision}

According to Metcalfe's law, the value of a network is proportional to the square of the network size. There is a positive feedback phenomenon in the environment of the internet economy; that is, marginal revenue increases with growing demand, marginal costs decrease with increasing demand, and the point where marginal revenue equals marginal cost is the positive feedback point. When the market demand is on the left side of the positive feedback point, the marginal revenue is less than the marginal cost; when the market demand is on the right side of the positive feedback point, the marginal revenue is greater than the marginal cost (Guo \& Yan, 2012; Guo et al., 2013). Here it can be understood that the user size that reaches the positive feedback point is the scale threshold value (also named user base or "installed base") for the development of the network platform. Therefore, the marginal revenue is greater than the marginal cost when the network scale is larger than the user base, then the law of increasing marginal benefit in network economy appears. In this case, sharing economy platforms would enter in income-generating phase at a fast-growing pace. In contrast, when the network scale is lower than the user base, the marginal cost is greater than the marginal revenue. In this case, the main goal is to increase the scale of users. The primary task here is not to achieve profitability, coinciding with the development model of internet-based platforms that suggests that investing comes first, then profit making, as well as the reality that user scale is regarded as an important factor in measuring the value of a network platform.

When the user scale of a sharing economy platform is lower than the threshold, and the number of users has not reached the basic scale stage. A more rational approach by a sharing economy platform would be to regard expanding user scale as the primary task and attracting users from the demand side through low-price strategies or subsidies while temporarily sacrificing short-term gains. First-ride free specials, discounts, and subsidies are commonly used in the marketing promotion stage of sharing economy platforms such as DiDi. Another way is to offer free rides at certain times during special holidays. These strategies effectively help the platform attract and increase their customer base. Ata certain size of customer base, there will be a surge and aggregation in demand.

When the user scale of a sharing economy platform is larger than the threshold, it will enter a rapid development stage: the market moves toward a saturated state when all platform users are active. In this case, the profit margin of the 
sharing economy platform increases, but for the purpose of recycling funds it may still choose a high price strategy. However, according to Equation (6), the degree of sensitivity of the expected transaction volumes to the price is related to the user size of the platform. As the user scale increases, the price elasticity of the expected volumes will also increase and when the sharing economy platform raises the price, the number of demand-side users who are price-sensitive will likely decrease. Of course, for mature markets, the quality-sensitive users who pursue high quality requirements will be also attracted to enter it. The user scale will be dynamically changed within the established range, and the pricing of the sharing economy platform will stabilize while overall revenue increases.

The above analysis is based on changes in the number of users on the demand side. For the sharing economy platform, the size of resource providers in the supply side determines the availability of sharing resources. The formation of a sharing economy market requires both a specific supply of resources and a certain scale of market demand. The difference is that in the sharing economy platform, each user can be a supplier or a demander, that is, the user has a dual identity depending on whether the user has idle resources that are consistent with the platform's positioning. Regardless of whether the supplier size is greater or less than the threshold, the platform will always encourage more resources to enter the platform through various means because the benefits of the sharing economy platform and resource suppliers are distributed by way of revenue sharing. Therefore, when the price is higher, the resource supplier can earn more, raising the supplier's willingness to join the platform. When the price is low, the sharing economy platform will need to adopt measures such as offering subsidies and incentives based on daily trading to encourage the resource suppliers to join or maintain the original supply. That is, from the perspective of the supply, the high price strategy is what the supplier wants. While from the perspective of the demand, the low price strategy is more attractive. The platform needs to continuously pay attention to the changes in the number of users, analyze the user composition and resources, and attract more demanders to join the platform while maintaining the supply resources at a given scale. The surge in market transactions is the source of profit for a platform.

Based on the data from DiDi, in 2017, the user size changed with price fluctuations. After DiDi raised the unit price of express significantly in April 2017 (see Figure 2), the number of consumers dropped sharply before improving, characterized by a V-shaped trend as shown in Figure 3. In such instances, as the consumer demand falls, the income of service providers (drivers) from the sharing platform will decrease.

\subsection{Analysis of Decision Preferences}

The decision preferences of sharing economy platforms may vary in the different stages of user scale development or with transitions in competitive positioning. There are three main types of such preferences: 


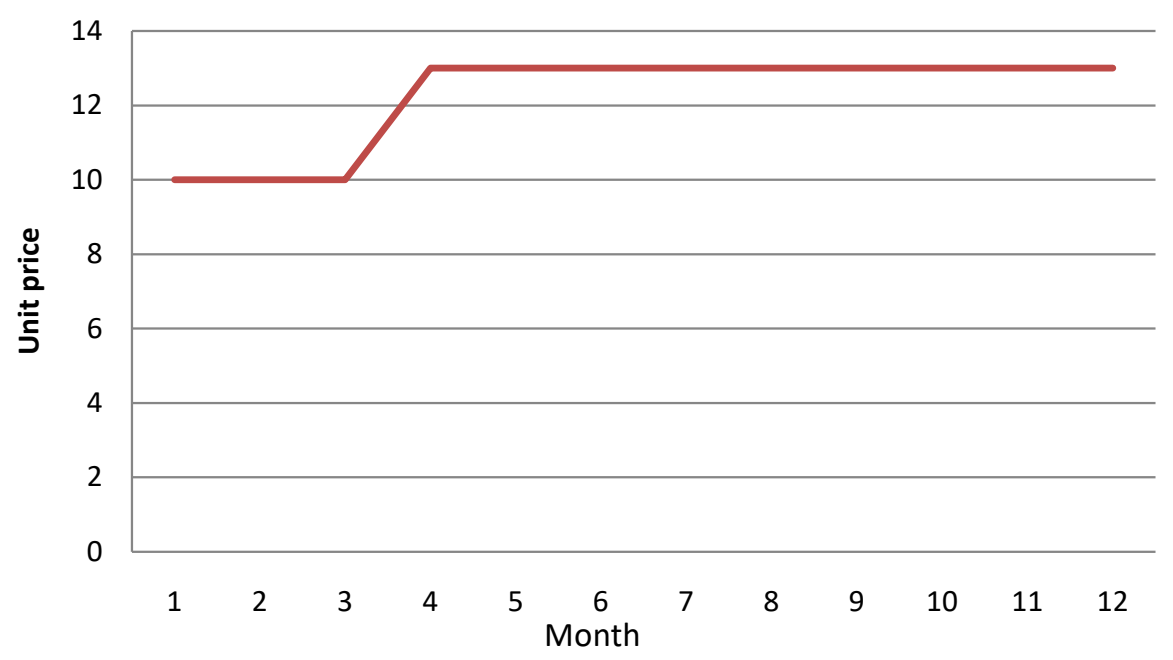

Figure 2. DiDi unit prices in 2017.

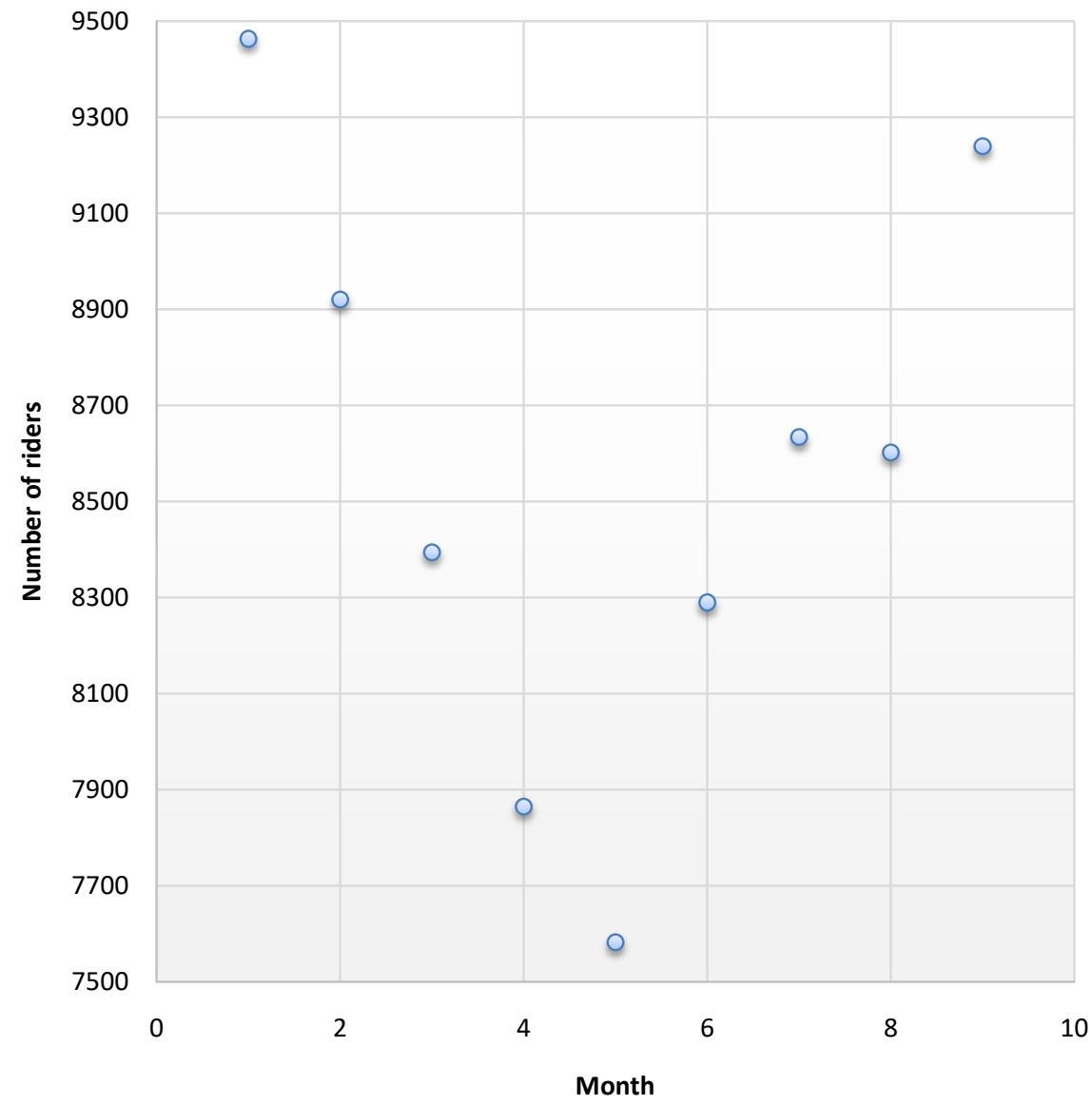

Figure 3. The number of DiDi consumers (riders) in 2017.

Profit preference, i.e. the decision maker tends to choose the optimal price for revenue maximization for the platform $p^{*}\left(\pi_{2}\right)$.

Demand preference, i.e. the decision maker tends to choose the lower price in order to avoid restraining demand. Based on the previously mentioned theorem, 
the pricing decision of the sharing economy platform is related to sharing costs of providers $\left(C_{1 f}\right)$. When $|\alpha|>1$, and if $C_{1 f}=0$, then the pricing decision of the sharing economy platform is $p^{*}\left(\pi_{2}\right)$. If $C_{1 f}>0$, the pricing decision of the sharing economy platform is uncertain. When $|\alpha|<1$, the sharing economy platform chooses the optimal price to ensure revenue maximization for both providers and the platform $\left(p^{*}(\pi)\right)$. When price elasticity is greater $(|\alpha|>1)$, the sharing costs of providers is the main factor determining whether the platform will choose the optimal price to ensure its own revenue maximization. On the other hand, if the sharing costs of providers $\left(C_{1 f}\right)$ is greater than zero, the sharing economy platform has to be more concerned about the revenue of providers to secure more transactions) is greater than zero, but the pricing decision is more uncertain. When price elasticity is lower $(|\alpha| \leq 1)$, the sharing economy platform chooses the optimal price to ensure revenue maximization for both providers and the platform $\left(p^{*}(\pi)\right)$.

Supply preference: the sharing economy platform pay more attention to the availability of shared resources. The platform chooses a high price strategy because it can increase the volume of supply. In the case of $|\alpha|>1$, the pricing decision of the platform is affected by the sharing costs of providers $\left(C_{1 f}\right)$. If $C_{1 f}=0$, the pricing decision of the platform is $p^{*}(\pi)$. If $C_{1 f}>0$, there will be uncertainty in pricing decision of the platform. In the case of $|\alpha| \leq 1$, the platform will choose the optimal price to maximize its own revenue.

Based on the above analysis, the different sharing costs of various resources affect the pricing decision of the sharing economy platform. Resources with lower sharing costs fit well with the sharing economy. This explains why the sharing economy is growing rapidly in some industries but not in others.

\subsection{Risk Analysis of Different Decision Preferences}

Sharing economy platforms share their income with the resource owners as a way to encourage them to join the platform (Ma \& Xu, 2018). For Example, to encourage higher driver participation, $\mathrm{DiDi}$ designed a series of incentive policies, like additional subsidies or incentives such as the morning peak subsidy and the machine bonus (i.e., bonus given out when the driver's consecutive orders reach a certain number). According to DiDi's policy, drivers will be rewarded if they provide continuous services with 12 orders per day. Of course, based on established income, the more profits the dripping platform shares with the driver, the less the income of the platform is (Kung \& Zhong, 2017). However, if the proportion of revenue to the drivers is reduced, the drivers' willingness to participate will be affected, which may cause the platform to lose vehicles.

At different stages of development, the platform will adopt suitable strategies. In the marketing stage, the sharing economy platform's primary task is to expand the user scale (Li, 2015). Rational decision makers may temporarily give up short-term profits and offer low prices to attract customers. Therefore, competitive threats from alternative products or services are lessened. In the example of 
$\mathrm{DiDi}$, the first order is free in the promotion phase and all kinds of rewards and subsidies are available. For consumers, DiDi has an absolute price advantage in the promotion stage. Therefore, it has higher user stickiness and lower risk of customer loss. In contrast, when the sharing economy platform lacks a competitive advantage over, users may choose other products and services.

The risk of resource loss is related to the idle cost of resources. The higher the idle cost per unit of resources, the higher the risk of resources loss is. The idle cost depends on the types and properties of the resources. For example, the idle cost of knowledge is less than that of a car or house. Therefore, the risk of loss is different for different types of resources. In order to avoid the loss of supply resources, the sharing economy platform has to sacrifice its own share of the proceeds from each unit transaction and share with its suppliers.

\section{Conclusion}

Based on the revenue sharing model built to analyze the pricing-setting behaviors of sharing economy platforms, this paper discusses the effects of resource-sharing costs and the price sensitivity of expected transaction volumes on the pricing decisions of sharing economy platforms, and then analyzes their decision tendencies at the different stages of user scale development and the risks of different decision preferences.

This study concludes that, when faced with different optimal price choices to ensure revenue maximization for the platform only, or both the platform and providers, the pricing decision, respectively, is related to the sharing costs of providers and price elasticity of expected transaction volume. In the case of variable costs of providers that are zero and price elasticity index equal to 1 , the two optimal prices are the same. In the case of variable costs of providers that are larger than zero and price elasticity index equal to 1, the optimal price for the platform's revenue maximization is higher. In the case of variable costs of providers that are zero and price elasticity index higher than 1 , the optimal price for the platform's revenue maximization is lower. In the case of variable costs of providers larger than zero and price elasticity index lower than 1, the optimal price for the revenue maximization of platform is higher. The sharing economy platform tends to choose a low price strategy when the user scale is below the user base; otherwise, it chooses a high price strategy.

Decisions based on different preferences have different pricing choices. When the platform has a "profit preference", it will choose an optimal price to ensure the maximization of its own revenue. When the platform has a "demand preference", it tends to choose a low price strategy and its price decision is affected by the sharing costs of providers and the price sensitivity of expected transaction volumes. When the platform has a "supply preference", it tends to choose a high price strategy. Similarly, its price decision is affected by the sharing costs of providers and the price sensitivity of expected transaction volumes. In addition, with different decision preferences, the platform will face different risks. A high 
price strategy may lead to a loss of users, while a low price strategy may lead to a loss of resources.

The contributions reveal that the price-setting decisions of platform are influenced by sharing costs of providers, user scale and price elasticity. Resources with lower sharing costs fit well with the sharing economy. This explains why the sharing economy is growing rapidly in some industries but not in others. And then this paper reveals the different pricing strategies of sharing economy in different stages of user scale development. The study significantly contributes to current literature because it considers how our new Internet-based society could potentially produce sustainable development by adjusting pricing strategies to adapt to market states. Sharing economy models are becoming ever more popular and changing the face of business models, prompting endeavors to understand their mechanisms, influencing factors, and profit determinants, among others. The study has the potential to reveals implications for sharing economy business managers, specifically in terms of giving insight about the best price-setting practices under different market situations.

The results of this study provide several theoretical and practical implications. In theory, these findings have more significance in prompting further research on the sharing economy, as well as help scholars to understand the mechanisms, influencing factors, and profit determinants of sharing economy platform's price-setting decision. Practically, the findings can be used for reference for the owners or managers, operators, and service providers of sharing platform, giving them insight about the best price-setting practices under different market situations. For new sharing platforms, they can get some inspiration to choose suitable pricing strategies according to the size of its customer base and its product life cycle stage. Furthermore, an effective revenue allocation mechanism is the key to the development of the sharing economy. In summary, it is crucial to design an effective pricing mechanism according to the different (marketing) stages of the sharing platform.

The limitation of this paper involves the many factors influencing changes in demand and the revenue of platform operators and service providers. These include related goods or services (even substitutes and complements in some cases), as well as consumer tastes and preferences, among others. However, this paper discusses pricing strategies without considering these other factors. Further research on this topic should consider consumer behaviors, tastes, and preferences, as well as the competitive environment.

\section{Acknowledgements}

This work was supported by the Beijing Philosophy and Social Science Research Program (grant number 17BGL033).

\section{Conflicts of Interest}

The authors declare no conflicts of interest regarding the publication of this paper. 


\section{References}

Andreoni, V. (2020). The Trap of Success: A Paradox of Scale for Sharing Economy and Degrowth. Sustainability, 12, 3153. https://doi.org/10.3390/su12083153

Armstrong, M. (2006). Competition in Two-Sided Markets. The RAND Journal of Economics, 37, 668-691. https://doi.org/10.1111/j.1756-2171.2006.tb00037.x

finance@china.org.cn (2018). Didi Completed 7.43 Billion Trips in 2017, with an Average of 5 Trips per Person. http://finance.china.com.cn/industry/20180109/4500857.shtml

Frenken, K., \& Schor, J. (2017). Putting the Sharing Economy into Perspective. Environmental Innovation and Societal Transitions, 23, 3-10. https://doi.org/10.1016/j.eist.2017.01.003

Gibbs, C., Guttentag, D., Gretzel, U., \& Morton, J. (2017). Pricing in the Sharing Economy: A Hedonic Pricing Model Applied to Airbnb Listings. Journal of Travel \& Tourism Marketing, 35, 46-56. https://doi.org/10.1080/10548408.2017.1308292

Guo, Y.-L., \& Yan, J.-Y. (2012). Coordination of IT Service Supply Chain (pp. 65-114). Beijing: Publishing House of Electronics Industry Press.

Guo, Y.-L., Chen, J.-B., Guo, H.-L., \& Lu, X.-M. (2013). Coordination Mechanism of SaaS Service Supply Chain: Based on Compensation Contracts. Journal of Industrial Engineering and Management, 6, 301-307. https://doi.org/10.3926/jiem.789

Hamari, J., Sjöklint, M., \& Ukkonen, A. (2016). The Sharing Economy: Why People Participate in Collaborative Consumption. Journal of the Association for Information Science and Technology, 67, 2047-2059. https://doi.org/10.1002/asi.23552

Hayek, F. A. (1945). The Use of Knowledge in Society. The American Economic Review, 35, 519-530.

Henten, A. H., \& Windekilde, I. M. (2016). Transaction Costs and the Sharing Economy. Info, 18, 1-15. https://doi.org/10.1108/info-09-2015-0044

Jiang, H. Y., \& Yin, Q. F. (2019). Research on Equilibrium Model of Shared Consumer Market. Finance and Trade Research, 2, 27-37.

Kannisto, P. (2017). Sharing for Profit: A New Business Model? Annals of Tourism Research, 66, 206-208. https://doi.org/10.1016/j.annals.2017.07.003

Kung, L.-C., \& Zhong, G.-Y. (2017). The Optimal Pricing Strategy for Two-Sided Platform Delivery in the Sharing Economy. Transportation Research Part E: Logistics and Transportation Review, 101, 1-12. https://doi.org/10.1016/j.tre.2017.02.003

Li, Q., \& Zhao, Y.-F. (2017). Analysis of Pricing Strategy for Container LCL Platform in the Sharing Economy. Logistics Science Technology, 40, 1-5 + 15.

Li, W.-M., \& Lu, F.-Y. (2015). Sharing the Origin and Reality of Economics. Reform, 12, 42-51.

Li, Y.-L. (2015). The Value Creation Model and Its Influence of Sharing Economy. Business Economics, 10, 116-117.

Lin, S.-Z. (2017). Research on Pricing Strategies of Online Dating Platforms and Car-Hailing Platforms. PhD Thesis, Guangzhou: South China University of Technology, China.

Ma, Q., \& Xu, H. (2018). Transaction Fee Regulation for Sharing Economy Platforms. Review of Industrial Economics, No. 1, 15-23.

Meade, J. (1986). Different Forms of Share Economy. London: Public Policy Center Press.

Nicosia, G., Pacifici, A., \& Pferschy, U. (2017). Price of Fairness for Allocating a Bounded Resource. European Journal of Operational Research, 257, 933-943. 
https://doi.org/10.1016/j.ejor.2016.08.013

Pang, J.-W., \& Chen, H. (2017). Sharing Economy-Meaning and Characteristics. Modern Management Science, 3, 36-38.

Puschmann, T., \& Alt, R. (2016). Sharing Economy. Business \& Information Systems Engineering, 58, 93-99. https://doi.org/10.1007/s12599-015-0420-2

Qi, H.-Y. (2017). Study on Pricing of Mobile Taxi Platform Based on Supply and Demand Condition. Master's Thesis, Nanjing: Nanjing University.

Qiao, H.-W., \& Zhang, J.-C. (2016). The Sharing Economy: A New Normal State of Economic Ethics. Tianjin Social Sciences, 3, 93-98.

Schwieterman, J. P., \& Bieszczat, A. (2017). The Cost to Car Share: A Review of the Changing Prices and Taxation Levels Ford Carsharing in the United States 2011-2016. Transport Policy, 57, 1-9. https://doi.org/10.1016/j.tranpol.2017.03.017

Selloni, D. (2017). New Forms of Economies: Sharing Economy, Collaborative Consumption, Peer-to-Peer Economy. In CoDesign for Public-Interest Services (pp. 15-26). Berlin: Springer International Publishing. https://doi.org/10.1007/978-3-319-53243-1 2

Shao, H.-B., \& Wang, S.-X. (2017). Sharing Economy and Value Creation. China Business and Market, 31, 100-109.

Wang, D., \& Nicolau, J. L. (2017). Price Determinants of Sharing Economy Based Accommodation Rental: A Study of Listings from 33 Cities on Airbnb.com. International Journal of Hospitality Management, 62, 120-131. https://doi.org/10.1016/j.ijhm.2016.12.007

Wang, L.-L. (2017). Research on the Mechanism of Sharing Economy Value Creation Based on O2O Perspective. Academy Forum, 4, 155-156.

Weitzman, M. L. (1984). The Share Economy: Conquering Stagflation. Cambridge, MA: Harvard University Press,

Weyl, E. G. (2010). A Price Theory of Multi-Sided Platforms. The American Economic Review, 100, 1642-1672. https://doi.org/10.1257/aer.100.4.1642

Wu, X.-J., \& Fang, Y. (2017). Pricing Strategy Analysis of Sharing Economic Platforms Based on the Two-Sided Markets Theory. Journal of Nanjing University of Finance \& Economics, 5, 28-36.

Wu, X.-J., \& Shen, J.-B. (2015). Connotation and Extension of Sharing Economy. Reform, 12, 52-60.

Xie, Z.-G. (2015). Analysis of Knowledge Economy of "Sharing Economy". Economic Perspectives, 12, 78-87.

Yan, J.-Y., Guo, Y.-L., \& Schatzberg, L. (2012). Coordination Mechanism of IT Service Supply Chain: An Economic Perspective. Electron Mark, 22, 95-103. https://doi.org/10.1007/s12525-012-0086-2

Zervas, G., Proserpio, D., \& Byers, J. (2013). The Rise of the Sharing Economy: Estimating the Impact of Airbnb on the Hotel Industry. Social Science Electronic Publishing, 16, $1-28$.

Zheng, Z.-L. (2016). Research on the Causes, Connotation and Business Model of Sharing Economy. Modern Economic Research, 411, 32-36.

Zhong, L., Xiao, L., \& Huang, X.-H. (2018). Analysis of Shared Bicycle Pricing Strategy and Sustainable Profit Model. Modern Business, 2, 64-65. 